\section{Normal Human Alveolar Macrophages Obtained by Bronchoalveolar Lavage Have a Limited Capacity to Release Interleukin-1}

\author{
Mark D. Wewers, Stephen I. Rennard, Allan J. Hance, \\ Peter B. Bitterman, and Ronald G. Crystal \\ Pulmonary Branch, National Heart, Lung, and Blood Institute, \\ National Institutes of Health, Bethesda, Maryland 20205
}

bstract. Interleukin-1 (IL-1) is a mediator released by stimulated mononuclear phagocytes that is thought to play an important role in modulating $\mathrm{T}$ and B lymphocyte activation as well as in contributing to the febrile response and other inflammatory processes. Circulating mononuclear phagocytes, blood monocytes, readily release IL-1 when stimulated. However, the ability of lung mononuclear phagocytes, alveolar macrophages, to dispose of the large daily burden of inhaled antigens without stimulating an inflammatory response suggests that the release of IL-1 by alveolar macrophages may differ significantly from that of blood monocytes. To evaluate this hypothesis, normal autologous alveolar macrophages, obtained by bronchoalveolar lavage, were compared with blood monocytes for their ability to release IL-1 in response to a standard stimulus, lipopolysaccharide (LPS). Alveolar macrophages were found to be at least 1,000 times less sensitive to LPS than blood monocytes. Furthermore, alveolar macrophages released significantly less IL-1 than blood monocytes $\left(26 \pm 11\right.$ vs. $128 \pm 21 \mathrm{U} / 10^{6}$ cells $\cdot 24 \mathrm{~h}$, respectively, after stimulation with $10 \mu \mathrm{g} / \mathrm{ml}$ of LPS, $P<0.001)$. This difference was not due to the release of substances by macrophages, which inhibited lymphocyte proliferation in response to IL-1, or to degradation of IL-1 by macrophages. Culturing macrophages in the presence of indomethacin and dialysis of macrophage supernatants did not affect the difference, and culturing macrophages with monocytes did not decrease detectable IL-1 activity from the monocytes. The IL-1 produced by the two cell

Address correspondence to Dr. Wewers, National Institutes of Health, Bethesda, MD.

Received for publication 13 December 1983 and in revised form 6 August 1984.

The Journal of Clinical Investigation, Inc.

Volume 74, December 1984, 2208-2218 types was indistinguishable by anion-exchange chromatography, gel filtration, and isoelectric focusing. In addition, consistent with the findings for alveolar macrophages, macrophages generated by the in vitro maturation of blood monocytes were also deficient in their ability to release IL-1. These findings suggest that if the population of alveolar macrophages obtained by bronchoalveolar lavage represents the total in vivo population of alveolar macrophages, although normal human macrophages are capable of IL-1 release, they are relatively limited in this ability, and this limitation seems to be linked to the maturational state of the mononuclear phagocyte. These observations may explain, in part, the ability of alveolar macrophages to clear the airspaces of foreign antigens without extensive activation of other pulmonary inflammatory and immune effector cells.

\section{Introduction}

In response to immune or inflammatory stimuli, cells of the mononuclear phagocyte system release interleukin-1 (IL-1), ${ }^{1}$ a $12-18,000-D$ protein that augments a variety of immune and inflammatory processes. For example, when blood monocytes are stimulated with a standard stimulus such as lipopolysaccharide (LPS), large amounts of IL-1 are released, and this IL-1 can magnify antigen- and mitogen-induced proliferation, enhance B lymphocyte immunoglobulin secretion, cause fever in laboratory animals, activate neutrophils, stimulate prostaglandin $E_{2}$ production by several target cells, stimulate the release of acute-phase reactants, and augment skin-fibroblast proliferation (1-18).

In this context, since the lower respiratory tract contains large numbers of mononuclear phagocytes (alveolar macrophages) that are constantly exposed to immune and inflammatory stimuli by virtue of their position in the airspaces, one might expect significant IL-1 release into the lower respiratory

1. Abbreviations used in this paper: FBS, fetal bovine serum; IL-1, interleukin-1; IL-2, interleukin-2; LPS, lipopolysaccharide. 
tract with a concomitant activation of immune and inflammatory processes. However, this does not appear to be the case. The $T$ and $B$ lymphocytes recovered from the lower respiratory tract of normal individuals show little evidence of activation, and few neutrophils are present (19). Furthermore, while alveolar macrophages can present antigen to autologous T lymphocytes (a process thought to require IL-1), human alveolar macrophages function much less efficiently than human blood monocytes in antigen presentation (20-22). Thus, it appears that alveolar macrophages are relatively deficient in accessory-cell function when compared with blood monocytes. A possible explanation for this deficiency in alveolar-macrophage accessory cell function is that alveolar macrophages are relatively limited in their ability to release IL-1. Such a limitation would help explain the ability of alveolar macrophages to handle the usual burden of inhaled material without inappropriately triggering immune and inflammatory responses.

In this regard, the present study was designed to compare IL-1 release by human alveolar macrophages with that of human blood monocytes in response to a standard stimulus. Both cell types were evaluated for $(a)$ their relative sensitivity to a standard stimulus, $(b)$ the amount of IL-1 released in response to the same stimulus, and $(c)$ the biochemical characteristics of the IL-1 released. In addition, since the alveolar macrophage represents a differentiated descendant of the blood monocyte, an in vitro analogue of monocyte maturation was examined to evaluate the effect of differentiation on the relative ability of the mononuclear phagocyte to release IL-1.

\section{Methods}

Isolation of alveolar macrophages and blood monocytes. Bronchoalveolar lavage cells were obtained from healthy normal subjects $(n=22)$ as previously described (19). Briefly, lavage of the right middle lobe, lingula, and left lower lobe was performed, instilling five $20-\mathrm{ml}$ aliquots of $0.9 \%$ sterile saline into each lobe, respectively. The saline was gently aspirated, the recovered fluid was pooled, and the cells were separated by centrifugation at $500 \mathrm{~g}$ for $5 \mathrm{~min}$. The cells were washed twice in RPMI 1640 (Microbiological Sciences, Inc., Elmsford, NY) containing penicillin $(100 \mathrm{U} / \mathrm{ml})$ and streptomycin $(100 \mu \mathrm{g} / \mathrm{ml})$ and resuspended at a concentration of $10^{7}$ cells $/ \mathrm{ml}$. Viability, as determined by the ability to exclude $0.2 \%$ trypan blue, always exceeded $95 \%$. Cell differentials were performed on Diff-Quick (American Hospital Supply Corp., McGaw Park, IL) stained cytocentrifuge preparations and in all cases showed alveolar macrophages $>90 \%$, lymphocytes $\leq 10 \%$, and polymorphonuclear leukocytes $<4 \%$.

In cases where the alveolar macrophage populations represented $<95 \%$ of the recovered cells, alveolar macrophages were further enriched by adherence to plastic. The recovered cells were plated at a density of $10^{6}$ cells $/ \mathrm{ml} \mathrm{RPMI} 1640$ with $50 \mu \mathrm{g} / \mathrm{ml}$ gentamicin $\left(2 \mathrm{~h}, 37^{\circ} \mathrm{C}, 95 \%\right.$ air-5\% $\mathrm{CO}_{2}$ ) in 24 well dishes (Costar, Cambridge, MA). Nonadherent cells were removed by repeated washings with RPMI 1640 and counted in a hemocytometer. The percentage of cells that remained adherent ranged between 70 and 90\%. Fresh complete medium (RPMI 1640 containing 5\% heat-inactivated fetal bovine serum [FBS; Associated Biomedics Systems Inc., Buffalo, NY] and $50 \mu \mathrm{g} / \mathrm{ml}$ gentamicin) was then added to the adherent cells. By morphological criteria these cells were always $>95 \%$ alveolar macrophages.

Blood mononuclear cells were obtained from heparinized venous blood taken from the normal subjects just before the bronchoalveolar lavage. The blood was diluted 1:1 with $0.9 \%$ saline (Biofluids, Inc., Rockville, MD), underlaid with lymphocyte separation medium (Litton Bionetics, Kensington, MD), and centrifuged at $200 \mathrm{~g}$ for $30 \mathrm{~min}$. The interface cells were aspirated from the gradient, washed three times in Hanks' balanced salt solution (HBSS; Microbiological Sciences, Inc.), counted in a hemocytometer, and reconstituted to $10^{7} \mathrm{cells} / \mathrm{ml}$ in RPMI 1640 with $50 \mu \mathrm{g} / \mathrm{ml}$ gentamicin. Cytocentrifuge preparations of this cell population consistently showed $\sim 20 \%$ monocytes, $80 \%$ lymphocytes, and $<1 \%$ neutrophils. To enrich the blood mononuclear cell populations for monocytes, the mononuclear cells were plated at a density of $2 \times 10^{6}$ cells $/ \mathrm{ml}$ in RPMI 1640 with $50 \mu \mathrm{g} / \mathrm{ml}$ gentamicin for $2 \mathrm{~h}$ at $37^{\circ} \mathrm{C}$ with $5 \% \mathrm{CO}_{2}$ in 24 well dishes (Costar). Nonadherent cells were removed by repeated washings and adherent cells were quantitated as done for the bronchoalveolar lavage cells. Adherent cells represented $25-50 \%$ of the original population and consisted of $60-90 \%$ (average $75 \pm 4 \%$ ) (all data are expressed as mean \pm SEM) monocytes with the remainder lymphocytes. Fresh complete medium was then added. These cells (referred to subsequently as monocytes) were then handled in an identical manner as the alveolar macrophages.

Assay for IL-1. Unless otherwise noted, IL-1 was quantified using the standard mouse thymocyte assay (23). Briefly, $\mathrm{C} 3 \mathrm{H} / \mathrm{HeJ}$ mice (The Jackson Laboratory, Bar Harbor, ME) 8-12 wk old were sacrificed by $\mathrm{CO}_{2}$ inhalation. Using aseptic technique, the thymus glands were removed, teased into a single-cell suspension with a 15-scalpel blade, passed through one layer of surgical gauze to remove particulates, washed twice in HBSS, and resuspended in RPMI 1640 for counting. The cells $\left(15 \times 10^{6} / \mathrm{ml}\right)$ were then placed into thymocyte medium [RPMI 1640 with $50 \mu \mathrm{g} / \mathrm{ml}$ gentamicin, $5 \%$ heat-inactivated FBS, and $2 \times 10^{-5}$ M 2-mercaptoethanol (Sigma Chemical Co., St. Louis, MO)]. Just before plating, $2 \mu \mathrm{g} / \mathrm{ml}$ phytohaemagglutinin (The Wellcome Foundation, Ltd., Beckenham, England) was added to the thymocyte suspension, and $100 \mu \mathrm{l}$ of the suspension $\left(1.5 \times 10^{6}\right.$ thymocytes) was plated into each well of a 96-well, round-bottomed microtiter plate (Linbro Chemical Co., Hamden, CT).

The samples to be evaluated for IL-1 activity were diluted in RPMI 1640 with $5 \%$ heat-inactivated FBS and added in $100-\mu 1$ aliquots to the thymocytes. Each dilution was assayed in triplicate. The cultures were incubated $\left(37^{\circ} \mathrm{C}, 95 \%\right.$ air $\left./ 5 \% \mathrm{CO}_{2}\right)$ for $48 \mathrm{~h}$, pulsed with $0.5 \mu \mathrm{Ci}$ of $\left[{ }^{3} \mathrm{H}\right]$ thymidine $(2 \mathrm{Ci} / \mathrm{mM}$; Amersham Corp., Arlington Heights, IL) per well, incubated for an additional $24 \mathrm{~h}$, harvested onto glass fiber filters using a cell harvester (MASH II, Microbiological Sciences, Inc.), and the incorporated radioactivity was quantified by scintillation counting.

Assay for interleukin-2. Supernatants were assayed for interleukin2 (IL-2) activity by their ability to stimulate the incorporation of $\left[{ }^{3} \mathrm{H}\right]$ thymidine by IL-2-dependent CT6 murine T lymphocytes, as previously described (24).

Quantitation of IL-1. IL-1 activity was quantified using probit analysis modified from the method of Gillis et al. (25). Briefly, each supernatant was assayed at fourfold dilutions (1:4-1:256) and the resulting thymocyte proliferation (as assessed by $\left[{ }^{3} \mathrm{H}\right]$ thymidine incorporation) was compared with that obtained from dilutions of a partially purified IL-1 standard. (The standard was prepared from LPS-treated human blood monocytes by DEAE chromatography as described below.) The value resulting from each dilution of the test sample was 
expressed as the percentage of thymocyte proliferation induced by the 1:20 dilution of the IL-1 standard; i.e., each value was expressed as: [(dpm of sample) $-(\mathrm{dpm}$ of medium control) $] \times 100 /[(\mathrm{dpm}$ of IL-1 standard) - (dpm of medium control)]. Each value was then plotted as a function of its reciprocal dilution on a $\log _{2}$ scale, thus generating a dilution curve for each sample. The reciprocal dilution of each sample that gave $50 \%$ of the maximum $\left[{ }^{3} \mathrm{H}\right]$ thymidine incorporation was determined and compared (on a linear scale) with the reciprocal dilution of the standard that gave $50 \%$ of its maximum value. The standard was arbitrarily assigned the value of $100 \mathrm{U}$.

In the example shown (Fig. 1), the reciprocal dilution of the standard that produced $50 \%$ of the maximum $\left[{ }^{3} \mathrm{H}\right]$ thymidine incorporation was 64; thus, by definition, the reciprocal dilution value of 64 corresponds to $100 \mathrm{U}$ of IL-1 activity. For the monocyte sample, the reciprocal dilution that produced $50 \%$ of the maximum $\left[{ }^{3} \mathrm{H}\right]$ thymidine incorporation was 125 ; thus, the monocyte sample was assigned $195 \mathrm{U}$ (i.e., [125/64] $\times 100 \mathrm{U}=195 \mathrm{U}$ ). The alveolar macrophage sample produced $50 \%$ of the maximum $\left[{ }^{3} \mathrm{H}\right]$ thymidine incorporation at a reciprocal dilution of 14 and thus was assigned $22 \mathrm{U}$ (i.e., $[14 / 64] \times 100=22 \mathrm{U}$ ).

Comparison of alveolar macrophages and monocyte release of

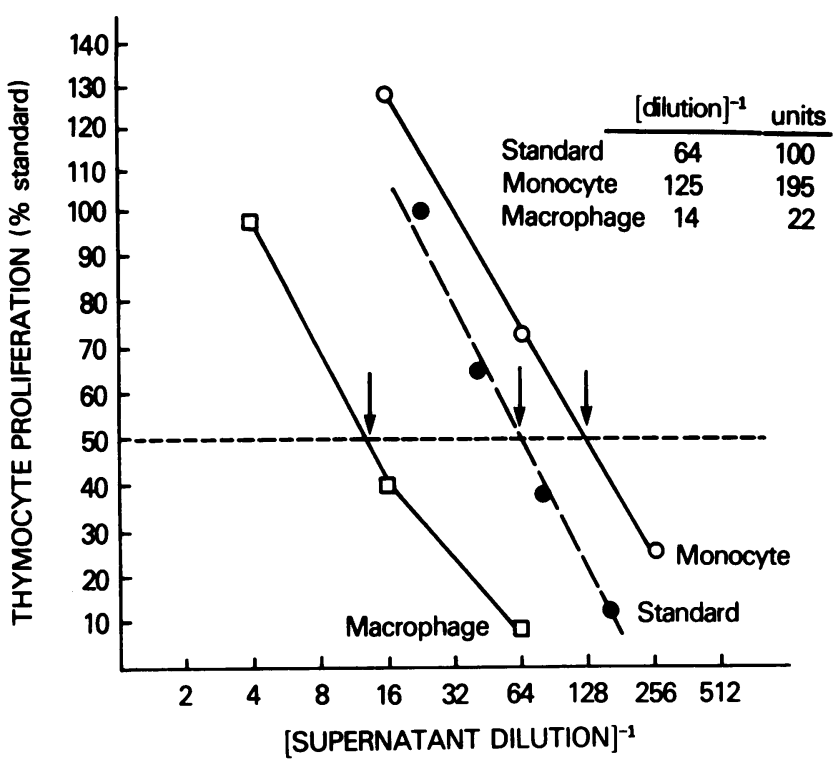

Figure 1. Quantitation of IL-1 using probit analysis. The amount of IL-1 in each supernatant sample was evaluated by determining thymocyte proliferation (assessed by $\left[{ }^{3} \mathrm{H}\right]$ thymidine incorporation) in response to increasing dilutions of the supernatants. In the example given, the dilution curve for the partially purified IL-1 standard (๑) is shown plotted with the test supernatants from alveolar macrophages $(\square)$ and blood monocytes ( $(0)$ from the same individual. Quantitation of IL-1 was accomplished by comparing the sample with the standard curve at the dilution that produced $50 \%$ of the maximum proliferation induced by the standard. In this example, $50 \%$ proliferation occurred for the standard at a dilution of 64 , which is arbitrarily defined as $100 \mathrm{U}$. The corresponding dilution at the $50 \%$ standard proliferation level was 125 for the monocyte sample (representing $195 \mathrm{U}$ ) and 14 for the macrophage sample (representing $22 \mathrm{U}$ ).
IL-1. Preliminary studies showed that incubation of monocytes in some batches of medium resulted in IL-1 release in the absence of the addition of exogenous stimulators of IL-1 release. Analysis of multiple lots of serum and medium components from several sources demonstrated that this spontaneous release of IL-1 correlated with the amount of endotoxin present as assayed by limulus amebocyte lysate gelation. These findings are consistent with previous observations of monocyte sensitivity to endotoxin $(26,27)$. However, when monocytes and alveolar macrophages were incubated in medium and serum that had been screened to eliminate endotoxin contamination, neither cell type spontaneously released IL-1. Furthermore, when a variety of stimuli including LPS, zymosan particles, Staphylococcus epidermidis, and ox erythrocyte-goat anti-ox erythrocyte immune complexes were tested, it was clear that LPS was the most potent stimulus for IL-1 release by both cell types (data not shown). For this reason, all subsequent experiments were performed in endotoxin-free medium using LPS as the standard stimulus.

To determine the relative sensitivity of alveolar macrophages and blood monocytes to LPS, alveolar macrophages and monocytes from six normal individuals were cultured in 24 well dishes (Costar) in complete medium at $10^{6} \mathrm{cells} / \mathrm{ml}$. The cells were incubated for $24 \mathrm{~h}$ with Escherichia coli LPS, Westphal preparation (Difco Laboratories, Inc., Detroit, MI), in amounts ranging from $10^{-14}$ to $10^{-5} \mathrm{~g} / \mathrm{ml}$. The supernatants were harvested, filtered through $0.22-\mu \mathrm{m}$ filters (Millipore Corp., Bedford, MA) to remove cells, and frozen at $-20^{\circ} \mathrm{C}$. All samples were assayed for IL-1 activity within 1 wk of harvesting.

To compare the relative amounts of IL-1 released by alveolar macrophages and monocytes maximally stimulated with LPS, alveolar macrophages and blood monocytes from 16 normal individuals were cultured in complete medium at $10^{6}$ cells $/ \mathrm{ml}$ in 24-well dishes (Costar) with or without $10^{-5} \mathrm{~g} / \mathrm{ml} \mathrm{LPS}$ for $24 \mathrm{~h}$. Supernatants were handled as described above.

Since microgram quantities of LPS can induce thymidine incorporation by $\mathrm{C} 3 \mathrm{H} / \mathrm{HeJ}$ mouse thymocytes, each thymocyte assay included a medium control containing $10^{-5} \mathrm{~g} \mathrm{LPS} / \mathrm{ml}$. In every instance, thymidine incorporation induced by medium containing LPS was approximately twice that induced by medium alone. When subjected to probit analysis, this nonspecific activity was insignificant compared with responses from stimulated mononuclear phagocyte supernatants ( $<1 \mathrm{U} / \mathrm{ml}$ for LPS medium control compared with an average 26 $\mathrm{U} / \mathrm{ml}$ for alveolar macrophage supernatants and $128 \mathrm{U} / \mathrm{ml}$ for blood monocyte supernatants).

Evaluation of role of inhibitors modulating the measurement of $I L-1$ released by macrophages and monocytes. Since prostaglandin $\mathrm{E}_{2}$ release may affect the proliferation of the thymocyte responder cells (28), alveolar macrophages and blood monocytes were incubated with indomethacin $\left(10^{-6} \mathrm{M}\right.$, Sigma) to determine if prostaglandin release by either of the two cell types influenced thymocyte proliferation. Indomethacin alone had no effect on the assay for IL-1 (data not shown). To test for the presence of dialyzable inhibitors in the cell supernatants that might suppress thymocyte proliferation, supernatants from monocytes and macrophage preparations stimulated with LPS were diluted 1:4 with complete medium and dialyzed against 1,000 vol of medium before assay. Finally, to determine if the alveolar macrophages might degrade released IL-1 or release nondialyzable inhibitors, monocytes plated at a density of $10^{6}$ cells/ml were cocultured with increasing numbers $\left(1.25 \times 10^{5}-10 \times 10^{5}\right.$ cells $\left./ \mathrm{ml}\right)$ of autologous alveolar macrophages. These co-cultures were stimulated and handled as previously described. 
Human $T$ cell assay for IL-1 activity. To validate that the difference observed between monocyte and alveolar macrophage IL-1 release was not related to the assay system used to detect IL-1, a similar study was carried out using human T lymphocytes as the detecting cell (10). Human peripheral blood mononuclear cells were isolated from buffy coat preparations obtained from normal donors using a lymphocyte separation medium gradient as described above. Monocytes were depleted by incubating the cells for $1 \mathrm{~h}$ at $37^{\circ} \mathrm{C}$ in $95 \%$ air $/ 5 \% \mathrm{CO}_{2}$, and removing the nonadherent cells by gently washing the culture plates. The $T$ lymphocytes in this preparation were then purified by rosetting with neuraminidase-treated sheep erythrocytes as previously described (29), and residual adherent cells were removed by culturing the cells overnight in a $100-\mathrm{mm}$ tissue culture dish in complete medium. The nonadherent population was then removed, washed twice in RPMI 1640, resuspended at $15 \times 10^{6}$ cells $/ \mathrm{ml}$ in heatinactivated FBS containing $10 \%$ dimethyl sulfoxide, frozen in vials (Nunc, Kampstrup, DK) in an automated cell freezer, and stored at $-70^{\circ} \mathrm{C}$ until use. Purity of the $\mathrm{T}$ cells as assessed by a $\mathrm{T}$ cell specific monoclonal antibody leu 4 (Becton Dickinson \& Co., Oxnard, CA) (30) was $>98 \%$ and cell viability always exceeded $90 \%$ as measured by trypan dye exclusion. On the day of assay, the $\mathrm{T}$ cells were rapidly thawed, washed three times in HBSS, and treated with anti-HLA-DR (Becton Dickinson) and rabbit complement (Cappel Laboratories, Cochranville, PA) to further deplete residual accessory cells. The remaining cells were washed twice in complete medium and were resuspended to $2 \times 10^{6}$ cells $/ \mathrm{ml}$ in thymocyte medium as described for the thymocyte assay. The assays for IL-1 using the human T cells were performed as described for the mouse thymocyte assay, with the exceptions that the final concentration of phytohemoglutinin used was $0.1 \mu \mathrm{g} / \mathrm{ml}$ and the final cell concentration was $10^{6}$ cells $/ \mathrm{ml}$.

Partial purification of alveolar macrophage and blood monocyte $I L-1$. Blood mononuclear cells were obtained from the leukopheresis of a normal subject, cultured for $2 \mathrm{~h}$ in serum-free RPMI 1640, washed free of nonadherent cells, and then incubated for $24 \mathrm{~h}$ in complete medium in the presence of LPS $(10 \mu \mathrm{g} / \mathrm{ml})$. Alveolar macrophages were cultured for $24 \mathrm{~h}$ in the presence of LPS $(10 \mu \mathrm{g} / \mathrm{ml})$ in complete medium. Supernatant fluids obtained from the culture of alveolar macrophage from several individuals were pooled.

$D E A E-52$ chromatography. Supernatants from monocytes and macrophage cultures were dialyzed at $4^{\circ} \mathrm{C}$ against $10 \mathrm{mM} \mathrm{NaCl}, 20$ $\mathrm{mM}$ Tris- $\mathrm{HCl}, \mathrm{pH} 7.5$, and applied to a $2.6 \times 10 \mathrm{~cm}$ column of DEAE52 cellulose (Whatman Ltd., Kent, England) that had been equilibrated in the same buffer. The column was eluted into 30 fractions using a 10-300 mM NaCl gradient. An aliquot of each fraction was diluted with RPMI 1640 containing 5\% FBS, and assayed as described above.

Sephadex G-100 chromatography. Aliquots from the peak activity of IL-1 obtained from the DEAE-52 chromatography were lyophylized, reconstituted in distilled water to effect a 10-fold concentration, and applied to a $1.6 \times 70-\mathrm{cm}$ column of superfine Sephadex G-100 (Pharmacia Inc., Piscataway, NJ), and the column was eluted with $100 \mathrm{mM}$ Tris $\mathrm{HCl}, 100 \mathrm{mM} \mathrm{NaCl}, \mathrm{pH} 7.40$, by gravity at a flow rate of $3 \mathrm{ml} / \mathrm{h}$.

Isoelectric focusing. Supernatant fluid $(100 \mathrm{ml})$ from blood monocyte or alveolar macrophage cultures was used for determining the isoelectric profile of IL-1 activity. The medium was dialyzed against $1 \%$ glycine, mixed with $5 \mathrm{~g}$ Ultradex (LKB Instruments, Inc., Rockville, MD) and $5 \mathrm{ml}$ of Biolyte 3-10 (Bio-Rad Laboratories, Richmond, CA), and poured onto a focusing plate (LKB Instruments, Inc.). Focusing was done at $8 \mathrm{~W}$ constant power for $15 \mathrm{~h}$ at $4^{\circ} \mathrm{C}$, and the resultant gradient was divided into 30 fractions. $1 \mathrm{ml}$ of de-ionized water was added to each fraction, and the $\mathrm{pH}$ was determined. Each fraction was dialyzed against phosphate buffered saline (pH 7.4), diluted with complete medium, filtered through $0.22 \mu \mathrm{m}$ filters, and assayed for IL-1 activity in the mouse thymocyte assay.

Monocyte maturation and $I L-1$ release. As an in vitro analogue of the maturation of monocytes into tissue macrophages, blood monocytes were allowed to mature in culture over an 11-d period. Maturation was confirmed by morphologic criteria. The cells were maintained at $10^{6} \mathrm{cells} / \mathrm{ml}$ in endotoxin-free complete medium. Monocytes were tested for their ability to release IL-1 into the medium by stimulating the cells for $24 \mathrm{~h}$ with $10 \mu \mathrm{g} / \mathrm{ml}$ of LPS beginning at day $0,1,2,3,4$, 7 , and 11 . Cell viability ( $>95 \%$ were viable at all time points) was assessed by trypan blue dye exclusion. Phagocytic function was evaluated by counting the percentage of cells able to phagocytose carbonyl iron particles (Sigma). Fibronectin released into the medium was measured by enzyme-linked immunosorbant assay (31). The molecular weight profile of newly synthesized secreted proteins was also determined by incubating cells for $24 \mathrm{~h}$ with $13.5 \mu \mathrm{Ci}\left[{ }^{35} \mathrm{~S}\right]$ methionine/ml $(1,485$ $\mathrm{Ci} / \mathrm{ml}$; Amersham) at the time points indicated above. Supernatants were harvested, centrifuged, and frozen. The proteins present in the supernatants were precipitated with ethanol, resuspended in electrophoresis sample buffer containing 2\% 2-mercaptoethanol, and electrophoresed into $10 \%$ sodium dodecyl sulfate-polyacrylamide gels (32). Autoradiograms were prepared by the method of Bonner et al. (33).

Preparation of supernatants from tissue macrophages other than alveolar macrophages. To compare the thymocyte mitogenic activity released from alveolar macrophage sources with that of other differentiated tissue mononuclear phagocytes, breast milk macrophages were isolated from the milk of five individuals by low-speed centrifugation, and peritoneal macrophages were obtained from the peritoneal fluid of one healthy female undergoing laparoscopy for an infertility evaluation.

These cells were cultured at $10^{6}$ cells $/ \mathrm{ml}$ as described for monocytes and alveolar macrophages. The supernatants were analyzed for IL-1 activity as described above.

Statistical analysis. Statistical significance was determined by the two-tailed $t$ test.

\section{Results}

Relative sensitivity and extent of response of normal human blood monocytes and alveolar macrophages to LPS. Although neither monocytes nor alveolar macrophages released IL-1 when cultured in endotoxin-free medium, both cell types released IL-1 when stimulated with $E$. coli endotoxin (LPS). However, while both cell types could release IL-1, there was a remarkable difference in the response of the two cell types to LPS, both in relative sensitivity to LPS and in the quantity of the IL-1 produced after maximal stimulation (Fig. $2 A$ ). In the six individuals studied quantitatively, blood monocytes released $124 \pm 26 \mathrm{U} / 10^{6}$ cells $\cdot 24 \mathrm{~h}$ of IL-1 at $10^{-9} \mathrm{~g} / \mathrm{ml}$ of LPS and $211 \pm 24 \mathrm{U} / 10^{6}$ cells $\cdot 24 \mathrm{~h}$ at $10^{-5} \mathrm{~g} / \mathrm{ml}$ of LPS. In marked contrast, alveolar macrophages released only $5 \pm 5 \mathrm{U} / 10^{6}$ cells $24 \mathrm{~h}$ of IL-1 at $10^{-9} \mathrm{~g} / \mathrm{ml}$ of LPS and $51 \pm 26 \mathrm{U} / 10^{6}$ cells $\cdot 24 \mathrm{~h}$ at $10^{-5} \mathrm{~g} / \mathrm{ml}$ of LPS. The IL-1 release by the two cell types differed significantly at both the $10^{-9}$ and $10^{-5} \mathrm{~g} / \mathrm{ml}$ level of LPS $(P<0.005$ and $P<0.02$, respectively). 


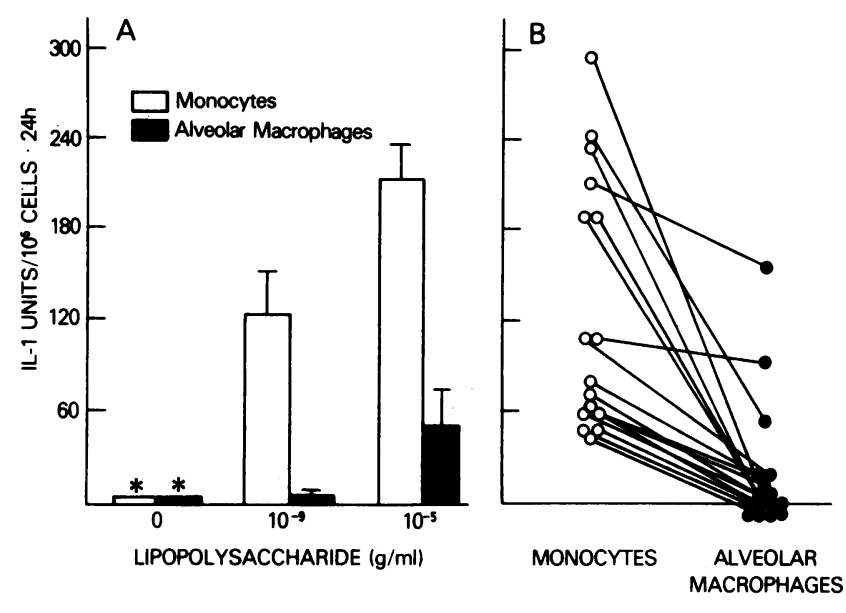

Figure 2. Comparison of the release of IL-1 by human blood monocytes and human alveolar macrophages in response to LPS. $(A)$ Comparison of IL-1 release at different amounts of LPS. Blood monocytes $(\square)$ and alveolar macrophages $(\square)$ from three normal individuals were cultured for $24 \mathrm{~h}$ at $37^{\circ} \mathrm{C}$ with medium alone or with $10^{-9}$ or $10^{-5} \mathrm{~g} / \mathrm{ml}$ of LPS. *, no detectable IL-1. (B) Comparison of the relative amount of IL-1 released by autologous human blood monocytes and alveolar macrophages in response to a standard stimulus. Blood monocytes $(0)$ and alveolar macrophages $(\bullet)$ from 16 normal individuals were cultured for $24 \mathrm{~h}$ at $37^{\circ} \mathrm{C}$ in the presence of $10^{-5} \mu \mathrm{g} / \mathrm{ml}$ LPS, and the amount of IL-1 released into the supernatant was quantified. A line connects the data for each individual.

In another series of experiments, IL-1 release by both cell types was measured qualitatively (thymocyte $\left[{ }^{3} \mathrm{H}\right]$ thymidine incorporation at a 1:4 dilution of supernatant from six individuals, using a much broader LPS dose range $\left[10^{-14}-10^{-5}\right.$ $\mathrm{g} / \mathrm{ml}]$ ). In this LPS range, monocytes invariably released detectable IL-1 activity at $10^{-12} \mathrm{~g} / \mathrm{ml}$ of LPS and in some cases at $10^{-14} \mathrm{~g} / \mathrm{ml}$ of LPS. In comparison, alveolar macrophages were much less sensitive. In no case was release of IL-1 by alveolar macrophages detectable at concentrations of LPS below $10^{-9} \mathrm{~g} / \mathrm{ml}$ (data not shown). Thus the blood monocytes were at least 1,000 times more sensitive to LPS than were the alveolar macrophages.

The quantitative comparison of IL-1 release was performed on the paired blood monocytes and alveolar macrophages of 16 normal individuals at a standard LPS dose of $10^{-5} \mathrm{~g} / \mathrm{ml}$. For each individual, on a per cell basis, blood monocytes invariably released more IL-1 than did their paired alveolar macrophages (Fig. $2 \mathrm{~B}$ ). On the average, blood monocytes released $128 \pm 21 \mathrm{U} / 10^{6}$ cells $\cdot 24 \mathrm{~h}$ and alveolar macrophages released $26 \pm 11 \mathrm{U} / 10^{6}$ cells $24 \mathrm{~h}(P<0.001)$. Two of the individuals studied were current smokers and their results did not differ from those of the group as a whole. Alveolar macrophages from eight of the individuals released no detectable IL-1 activity, but IL- 1 was released in every instance from the blood monocytes.
To evaluate the possibility that inhibitors produced by the alveolar macrophages or blood monocytes interfered with the ability of the mouse thymocytes to respond to IL-1, alveolar macrophages and blood monocytes were stimulated with endotoxin and cultured in the presence of indomethacin (Table I). Culturing alveolar macrophages in the presence of indomethacin did not enhance measurable IL-1 activity. Culturing blood monocytes in the presence of indomethacin likewise had no significant effect on IL-1 activity. Furthermore, dialysis of the supernatants before assay was also ineffective in significantly altering the detectable IL-1 activity in either the alveolar macrophage or monocyte samples.

To exclude the possibility that alveolar macrophages may produce an inhibitor that is not dialyzable and whose synthesis is not blocked by indomethacin, or the possibility that alveolar macrophages may absorb or degrade IL-1 present in the culture medium, alveolar macrophages were co-cultured with blood monocytes during LPS stimulation. Culture of monocytes in the presence of alveolar macrophages at a ratio as high as 1:1 did not reduce the apparent IL-1 activity produced by stimulated monocytes (Table I).

To insure that the observed differences in IL-1 release by alveolar macrophages and blood monocytes were not peculiar to the mouse thymocyte assay, the supernatants of alveolar macrophages and blood monocytes were also evaluated for IL-1 activity using a second assay in which human $T$ cells

Table I. Evaluation of the Possible Role of

Inhibitors Modulating the Measurement of IL-I Released by Macrophages and Monocytes

\begin{tabular}{ll}
\hline Condition & IL-1 \\
\hline & $\left(\mathrm{U} / 10^{6} \mathrm{cells} \cdot 24 \mathrm{~h}^{*}\right)$ \\
Alveolar macrophage supernatants & $6.4 \pm 0.8$ \\
Macrophages cultured with indomethacin $\ddagger$ & $6.5 \pm 0.9$ \\
Supernatants dialyzed before assay§ & $7.4 \pm 0.9$ \\
Blood monocytes supernatants & $53 \pm 3.0$ \\
Monocytes cultured with indomethacin $\ddagger$ & $66 \pm 8.4$ \\
Supernatants dialyzed before assay $\$$ & $63 \pm 3.2$ \\
Monocytes co-cultured with alveolar & \\
macrophages & \\
$+1.25 \times 10^{5}$ macrophages & $47 \pm 2.0$ \\
$+2.5 \times 10^{5}$ macrophages & $52 \pm 3.0$ \\
$+5.0 \times 10^{5}$ macrophages & $53 \pm 5.0$ \\
$+10.0 \times 10^{5}$ macrophages & $54 \pm 3.0$
\end{tabular}

* Amount of IL-1 released into medium in response to LPS (10 $\mu \mathrm{g} /$ $\mathrm{ml}$ ).

$\ddagger$ Cells incubated with indomethacin $\left(10^{-6} \mathrm{M}\right)$ at time of stimulation with LPS.

§ Supernatants were dialyzed against 1,000 vol of RPMI 1640 .

"Monocytes cultured at $10^{6}$ cells $/ \mathrm{ml}$ were incubated with increasing numbers of autologous alveolar macrophages. 
served as the responding cell. IL-1 activity in supernatant fluid from cultures of LPS-stimulated blood monocytes and alveolar macrophages from three normal individuals were assayed using the human $\mathrm{T}$ lymphocyte assay. The results obtained using the human $T$ lymphocyte assay closely paralleled results obtained using the mouse thymocyte assay. In each instance, the monocyte supernatant contained more activity than the macrophage supernatant $(P<0.05$, data not shown).

Finally, to demonstrate that the observed IL-1 activity was not due to contaminating IL-2, samples were also tested for their ability to promote proliferation of the IL-2-dependent CT-6 T lymphocyte cell line. In no instance did alveolar macrophage or blood monocyte supernatants contain detectable IL-2 activity.

Comparison of the biochemical properties of alveolar macrophage and blood monocyte $I L-1$. By several biochemical criteria, human blood monocyte and alveolar macrophage IL-1 were similar. IL-1 activity from blood monocytes $\left(10^{9}\right.$ cells) and alveolar macrophages ( $10^{9}$ cells) eluted from DEAE52 at the same ionic strength (Fig. 3). Furthermore, samples

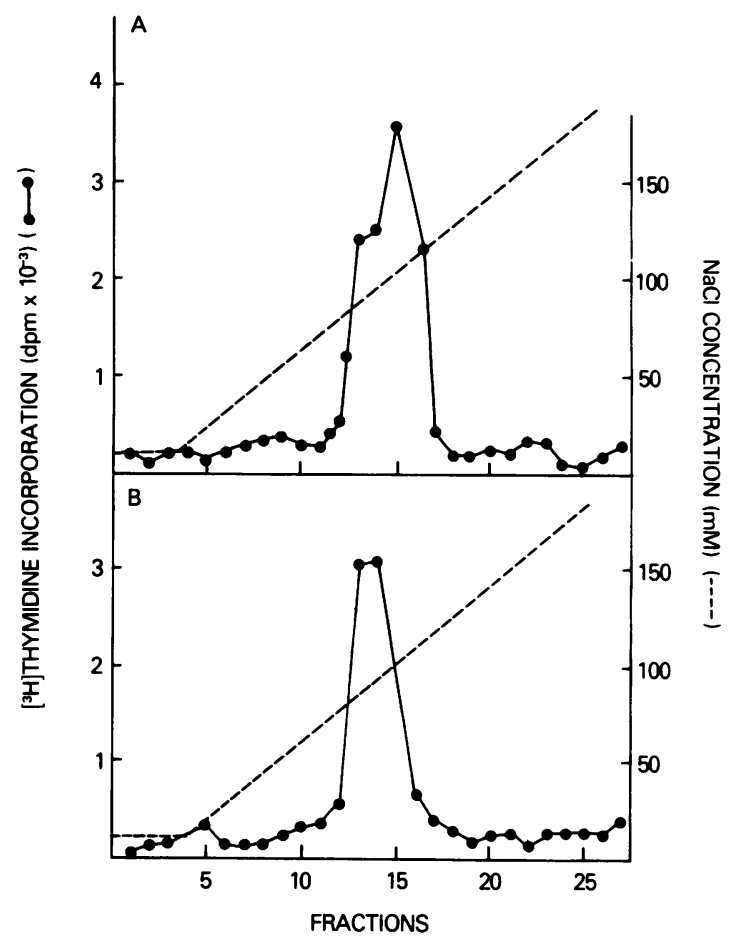

Figure 3. Comparison of DEAE-cellulose anion exchange chromatography of IL-1 released by human monocytes and alveolar macrophages. Supernatants from LPS-stimulated monocytes $\left(10^{9}\right.$ cells) and LPS-stimulated alveolar macrophages $\left(10^{9}\right.$ cells) were chromatographed on DEAE-cellulose using a $10-300 \mathrm{mM} \mathrm{NaCl}$ gradient. (A) The elution pattern for blood monocyte IL-1 (fractions diluted 1:100). (B) Elution pattern for alveolar macrophage IL-1 (fractions diluted 1:10). The dashed lines represent the $\mathrm{NaCl}$ gradient. taken from the peak fractions of the DEAE column demonstrated that both monocyte and macrophage IL-1 activity eluted on Sephadex G-100, just preceding the cytochrome $c$ marker corresponding to an estimated molecular weight of 13,000 (Fig. 4). In addition, the isoelectric points for monocyte and alveolar-macrophage IL-1 activity were very similar (Fig. 5), with both monocyte and macrophage IL-1 focusing consistently at an isoelectric point of $\sim 6.8$ and a somewhat more heterogeneous activity focusing at an isoelectric point between 5.2 and 5.4 .

Although the IL-1 from the two cell types was biochemically indistinguishable, a semiquantitative comparison of the net IL-1 activity, obtained by DEAE-52 anion exchange followed by Sephadex G-100 molecular sieving, demonstrated a significantly better yield from blood monocytes. For example, a 1:100 dilution of the blood monocyte DEAE-52 fraction produced activity similar to that of a 1:10 dilution of the alveolar macrophage DEAE-52 fractions. Similarly, after equal

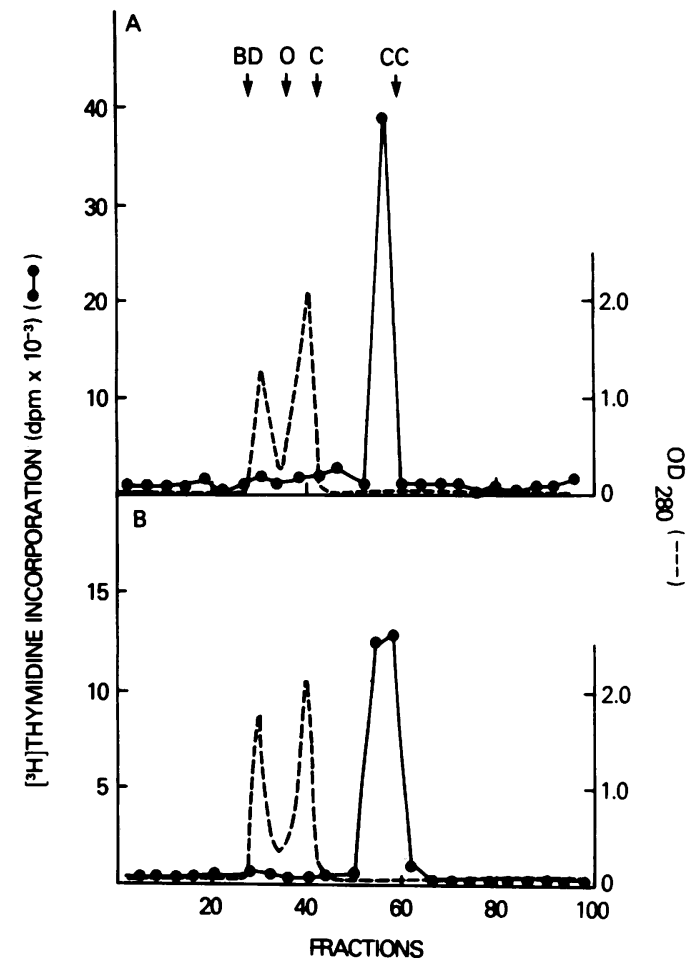

Figure 4. Comparison of Sephadex G-100 chromatography of DEAEcellulose partially purified IL-1 released by blood monocytes and alveolar macrophages. Peak fractions $(10 \mathrm{ml})$, each from the DEAEcellulose column (Fig. 3), were concentrated to $1 \mathrm{ml}$ and chromatographed by Sephadex G-100 gel filtration. $(A)$ Blood monocytes (fractions diluted 1:10). (B) Alveolar macrophages (fractions diluted 1:10). Standards (arrows) include: blue dextran (BD, $2 \times 10^{6} \mathrm{D}$ ), and cytochrome $c(\mathrm{CC}, 12,000 \mathrm{D})$. The dashed lines represent the optical density of eluted fractions at $280 \mathrm{~nm}$. 


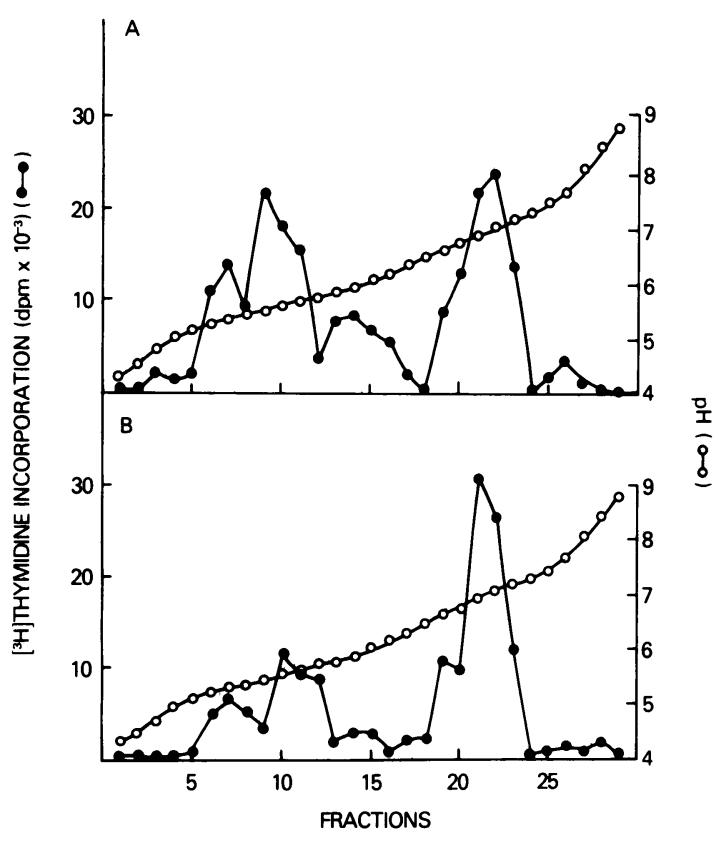

Figure 5. Comparison of the isoelectric focusing profile of IL-1 released by monocytes and alveolar macrophages. Supernatants from LPS-stimulated monocytes and alveolar macrophages were dialyzed into $1 \%$ glycine and focused for $15 \mathrm{~h}$ at $8 \mathrm{~W}$ constant power. IL-1 activity was measured after dialysis. $(A)$ Blood monocytes. $(B)$ Alveolar macrophages.

volumes from the DEAE-52 peaks were individually applied to Sephadex G-100 sieving, a 1:10 dilution of the fractions demonstrated a significantly better yield from the monocyte preparation.

Monocyte maturation and $I L-1$ release. Monocytes stimulated with LPS from time 0 until day 1 released large amounts of IL-1 activity ( $74 \mathrm{U} / 10^{6}$ cells $\cdot 24 \mathrm{~h}$; Fig. $6 \mathrm{~A}$ ). However, monocytes maintained in culture for $1 \mathrm{~d}$ before being stimulated with LPS released $<5 \mathrm{U} / 10^{6}$ cells $\cdot 24 \mathrm{~h}$, and those maintained for $48 \mathrm{~h}$ no longer could be stimulated to release detectable IL-1. In marked contrast, these same monocytes maintained the ability to phagocytize carbonyl iron particles (Fig. $6 \mathrm{~B}$ ), and by day 11 in culture were secreting large amounts of fibronectin (Fig. $6 \mathrm{C}$ ). Furthermore, while the cultured monocytes could not produce detectable IL-1, the sodium dodecyl sulfate-polyacrylamide gel electrophoresis pattern of the $\left[{ }^{35} \mathrm{~S}\right]$-methionine-labeled newly synthesized and secreted proteins suggested that these in vitro matured monocytes were capable of protein synthesis and secretion, and that some of the newly synthesized and secreted proteins at $11 \mathrm{~d}$ of maturation were different than those synthesized and secreted by day 1 (Fig. 6 D).

Analysis of IL-1-like activity from tissue macrophages other than alveolar macrophages. To compare the observed alveolar macrophage release of IL-1 to other tissue macrophage sources, thymocyte-mitogenic activity generated by normal human breast milk macrophages from five individuals and normal human peritoneal macrophages from one individual were also studied. Of the crude supernatants evaluated from breast milk macrophages cultured in the presence of $10^{-5} \mathrm{~g} \mathrm{LPS} / \mathrm{ml}$, three released no detectable thymocyte mitogenic activity at $24 \mathrm{~h}$, while the remaining two released 11 and $13 \mathrm{U}$, respectively. The one source of peritoneal macrophages released $53 \mathrm{U} / 10^{6}$ cells $\cdot 24 \mathrm{~h}$. Although we do not have detailed biochemical confirmation that this activity resembles IL-1, nor have we evaluated these sources for the production of inhibitors to thymocyte mitogenesis, these preliminary results from other nonelicited sources of normal human tissue macrophages parallel the results with alveolar macrophages.

\section{Discussion}

IL-1 is a mononuclear phagocyte-derived protein that augments T-lymphocyte replication, enhances B-lymphocyte immunoglobulin secretion, initiates the febrile response, activates neutrophils, stimulates prostaglandin $\mathrm{E}_{2}$ production by several cell types, triggers the release of acute phase reactants such as serum amyloid A, and augments skin fibroblast growth (1-18). The present study demonstrates that blood monocytes and alveolar macrophages can release IL-1 and that the molecules released are biochemically indistinguishable. However, there is a marked difference in the amounts of IL-1 these two cell types release. Importantly, in response to the same standard stimulus, on a per cell basis, alveolar macrophages release about fivefold less IL-1 than do autologous blood monocytes. Furthermore, blood monocytes matured in vitro rapidly lose the ability to release IL- 1 . This maturational change parallels the differences observed between blood monocytes and alveolar macrophages and suggests that relative to its precursor cell, the alveolar macrophage has a limited ability to release IL-1.

IL-1 release by human alveolar macrophages. When stimulated, normal human alveolar macrophages release IL-1 with properties very similar to the IL-1 released by human blood monocytes. The human alveolar macrophage and blood monocyte IL-1 demonstrated similar chromatographic behavior on ion-exchange chromatography, gel filtration, and isoelectric focusing. Furthermore, these properties are generally similar to the known properties of IL-1 released by human blood monocytes, human monocytic leukemia cells, human placental mononuclear phagocytes, transformed human lines, rabbit alveolar macrophages, and transformed murine macrophages (34-40). In addition to sharing biochemical properties with human blood monocyte IL-1, human alveolar macrophage IL-1 demonstrates similar biologic behavior in its ability to stimulate the proliferation of mouse thymocytes and highly purified human blood $\mathrm{T}$ cells. Thus, while differences may 

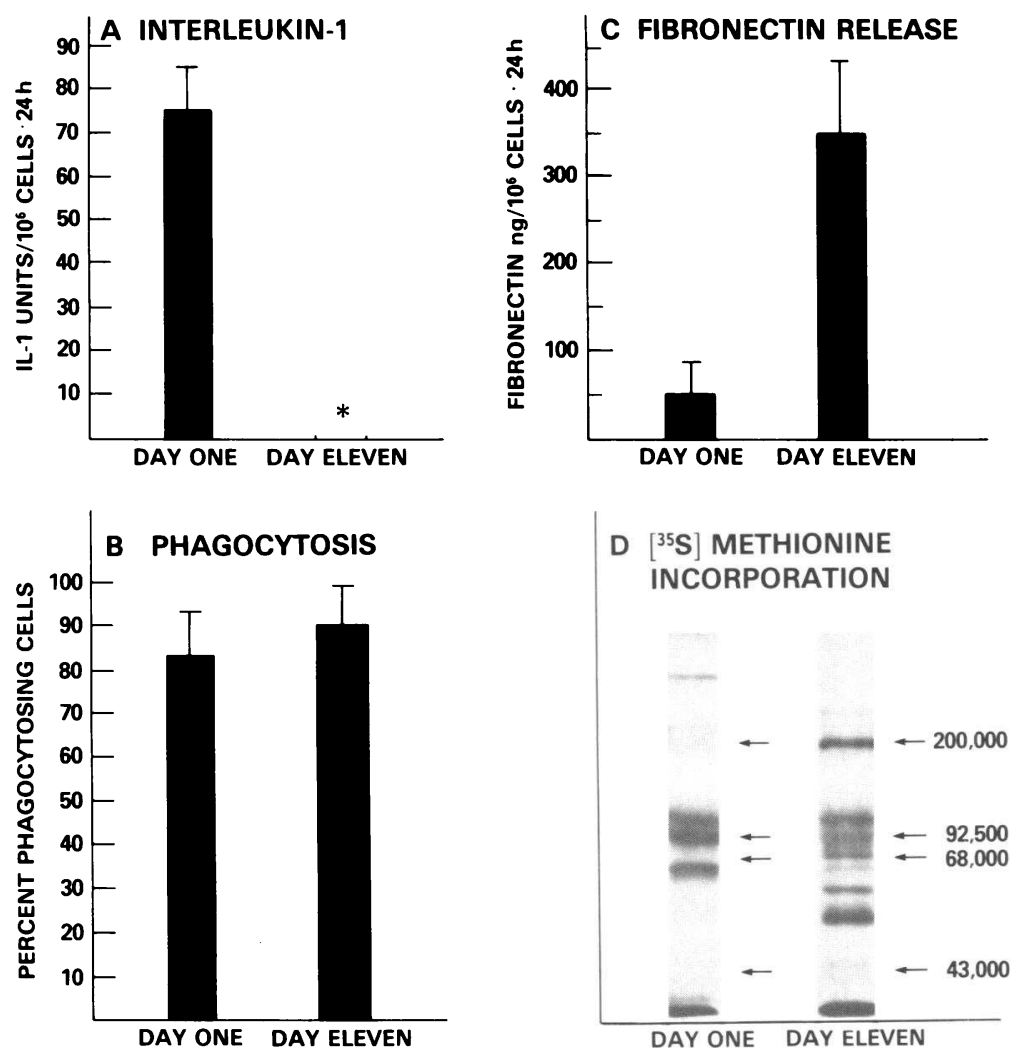

Figure 6. Effect of in vitro maturation on blood monocyte release of IL-1 compared with other monocyte functions. Blood monocytes were cultured from 1 to $11 \mathrm{~d}$ and stimulated with LPS $(10 \mu \mathrm{g} / \mathrm{ml})$ for $24 \mathrm{~h}$ before harvesting the supernatant. Shown are the results for day 1 and day 11 for $(A)$ IL-1 release; *, no detectable IL-1; $(B)$ phagocytosis of carbonyl iron particles; $(C)$ fibronectin release; and $(D)$ SDS-polyacrylamide gel electrophoresis of $\left[{ }^{35} \mathrm{~S}\right]$ methionine incorporated and released protein.

appear when the alveolar macrophage-derived IL-1 is purified to homogeneity and subsequently analyzed, the present data suggest that such differences, if any, will be minor.

Relative capacity of human alveolar macrophages to release $I L-1$. Strikingly, although the IL-1 of blood monocytes and alveolar macrophages is functionally and biochemically similar, the alveolar macrophage is clearly limited in its capacity to release this macromolecule. Several findings suggest this is an inherent property of the alveolar macrophage, and not a result of the in vitro conditions or the detection systems used. First, although individuals varied in the amount of IL-1 released by their monocytes and alveolar macrophages, in each case their monocytes produced more than did the alveolar macrophages for the same stimulus. Second, not only did the alveolar macrophages release less IL-1 than did the monocytes, but the alveolar macrophages were also less sensitive to a standard stimulus than the blood monocytes. Third, culturing alveolar macrophages in the presence of indomethacin, dialyzing macrophage supernatants, and subjecting macrophage supernatants to gel filtration did not unmask previously inhibited IL-1 activity, nor did co-culturing alveolar macrophages with blood monocytes inhibit blood-monocyte release of IL-1 activity. Fourth, the difference in the relative amount of IL-1 released by monocytes and alveolar macrophages was similar whether an assay system using mouse thymocytes or human T-cells as responder cells was used. Fifth, the measured IL-1 activity was not an artefact of IL-2 contamination, since the IL-2 assay failed to detect IL-2 activity. Sixth, the relative differences between the amount of IL-1 released by monocytes and alveolar macrophages were noted in response to stimuli other than LPS, including immune complexes, zymosan, and heatkilled bacteria, demonstrating that this difference is not stimulus specific.

Additional support for the concept that lung-mononuclear phagocytes differ from blood monocytes in their ability to release IL-1 can be inferred from the work by Atkins et al., demonstrating that mononuclear cells were sources of endogenous pyrogen (i.e., likely IL-1) (41). When equivalent numbers of mononuclear cells were compared, rabbit blood mononuclear cells released significantly more endogenous pyrogen than rabbit lung mononuclear cells, suggesting that $(a)$ rabbit alveolar macrophages release less IL-1 than rabbit blood monocytes in response to a standard stimulus, and $(b)$ a pyrogen assay system also detects the difference in the relative amount of IL-1 released by lung- and blood-mononuclear phagocytes.

One hypothesis to explain this difference between the capacity of blood monocytes and alveolar macrophages to release IL-1 is that monocytes lose the ability to release significant amounts of IL-1 as they mature into alveolar macrophages. In this context, since alveolar macrophages are 
a part of the mononuclear phagocyte system, and since the blood monocyte is the precursor of the alveolar macrophage (42), one model of mononuclear phagocyte differentiation is to maintain the monocytes in culture for several days. Under these conditions, the monocytes spread out and take on many of the morphologic and functional characteristics of alveolar macrophages (43-46). If this model is accepted as a reasonable parallel of the in vivo situation, then further support for the concept that alveolar macrophages have a limited capacity to release IL-1 comes from the data presented here, as well as in previous reports $(11,46)$ that blood monocytes maintained in culture rapidly lose their ability to release IL-1 in response to a standard stimulus. This observation is even more striking in the context of the findings that these cells remain viable, can phagocytose, continue to synthesize protein, and secrete more fibronectin than freshly cultured blood monocytes.

That this limited release of IL-1 by alveolar macrophages and in vitro matured macrophages may also be characteristic of other mature tissue macrophages is implied by the results obtained from peritoneal macrophages and breast milk macrophages. However, given the limited number of subjects evaluated, we are reluctant to generalize the results with alveolar macrophages to all tissue macrophages.

Why alveolar macrophages are relatively limited in their ability to release $I L-1$. One explanation, implied by the in vitro monocyte maturational studies, is that since the ability to release IL-1 decreases significantly with mononuclear phagocyte maturation, the IL-1 detected in the alveolar macrophage cultures is actually being produced primarily by the young, newly recruited cells that have not yet differentiated fully into mature alveolar macrophages. In this context, the limited release of IL-1 by resident alveolar macrophages may simply reflect a limited number of recently recruited mononuclear phagocytes. Indirect evidence in support of this concept is provided by studies demonstrating that BCG administration will cause a rapid influx of circulating monocytes into the lungs (42) and that BCG administration can induce an alveolar macrophage population that is enhanced in its ability to release IL-1 (38). Therefore, if indeed young mononuclear phagocytes are the prime source of IL-1, it may be that IL-1 release in the lung is regulated, at least in part, by factors that control the influx of young monocytes.

Against this concept, however, are studies in a murine system demonstrating no correlation between the percentage of peroxidase-positive peritoneal mononuclear phagocytes (i.e., younger mononuclear phagocytes) and the ability of these cells to release IL-1 (47). In addition, Whisler et al. (12) have shown that human monocyte subsets, as defined by the presence or absence of complement receptors, differ 4-12-fold in their ability to release IL-1. Thus, a second explanation for the alveolar-macrophage limitation in IL-1 release (albeit not entirely separate from the maturational concept) is that IL-1 is released only by a subpopulation of mononuclear phagocytes that are normally underrepresented in the lung.
Another explanation for the observed limitation in alveolar macrophage IL-1 release is that the lung cells obtained by bronchoalveolar lavage may not represent the total alveolar macrophage population. That is, maybe lavageable alveolar macrophages are a select group of mononuclear phagocytes that have either already been stimulated to release IL-1 and hence have repressed their IL-1 release, or they are simply senescent cells with depressed overall metabolic function. This is a methodological problem inherent to all bronchoalveolar lavage studies.

A final explanation of why alveolar macrophages are limited in their ability to release IL-1 may be found in the marked differences in sensitivity to LPS between alveolar macrophages and blood monocytes. Whereas blood monocytes invariably responded to $10^{-12} \mathrm{~g} \mathrm{LPS} / \mathrm{ml}$, alveolar macrophages did not respond to amounts $<10^{-9} \mathrm{~g} \mathrm{LPS} / \mathrm{ml}$. Therefore, alveolar macrophages may not sense potentially immunogenic material in the same way as do blood monocytes, and are hence better suited for an environment of continual antigenic loading.

Interestingly, the use of LPS to demonstrate the relative inability of alveolar macrophages to produce IL-1, compared with blood monocytes, pointed out the high sensitivity of blood monocytes to endotoxin. Detecting $10^{-12} \mathrm{~g} \mathrm{LPS} / \mathrm{ml}$ far exceeds the sensitivity of the standard limulus amebocytelysate gelation assay. Duff and Atkins (26) compared the sensitivity to LPS of blood monocyte-endogenous pyrogen production and limulus amebocyte-lysate gelation, and found monocyte-endogenous pyrogen production to be 10 -fold more sensitive to LPS. Since endogenous pyrogen and IL-1 are indistinguishable, and since the mouse thymocyte is $10^{3}-10^{4}$ times more sensitive to IL-1-endogenous pyrogen than is the rabbit pyrogen assay (48), it is reasonable that the mouse thymocyte assay can detect $10^{5}$-fold lower amounts of endotoxin than standard limulus amebocyte lysate gelatin (using freshblood monocytes as endotoxin detectors and thymocyte-mitogenic activity as the response).

Consequences of the relative impotence of alveolar macrophages as producers of IL-1. Although the release of IL-1 by mononuclear phagocytes is thought to play a central role in a number of immune and inflammatory processes (1-18), in the context of the lung, the most important local effects are probably those related to mononuclear phagocyte-mediated responses to antigens. In this regard, the fact that alveolar macrophages have a limited capacity to release IL-1 may be responsible, at least in part, for the relatively subdued response of the pulmonary immune system to antigen stimulation compared with blood, i.e., IL-1 may play a rate-limiting role in the ability of the antigens that reach the lung to induce $T$ lymphocyte proliferation and immunoglobulin production. Since the lung is one of the sites in the body where there is high antigen load, this may be one mechanism that limits the immune response. However, when the population of alveolar macrophages changes, as occurs in many chronic inflammatory 
lung disorders, it is possible that the immune response within the lower respiratory tract may be significantly altered.

\section{Acknowledgments}

We would like to thank Alain Venet for his helpful suggestions, Gerald Fells for his expert technical advice, and Paula Pinkston for performing the IL-2 assays.

\section{References}

1. Mizel, S. B., and A. Ben-Zvi. 1980. Studies on the role of lymphocyte activating factor (interleukin-1) in antigen induced lymph node lymphocyte proliferation. Cell. Immunol. 54:382-389.

2. DeFreitas, E. C., R. W. Chestnut, H. M. Grey, and J. M. Miller. 1983. Macrophage-dependent activation of antigen-specific T-cells requires antigen and a soluble monokine. J. Immunol. 131:23-29.

3. Scala, G., and J. J. Oppenheim. 1983. Antigen presentation by human monocytes: evidence for stimulant processing and requirement for interleukin-1. J. Immunol. 131:1160-1166.

4. Rosenwasser, L. J., and C. A. Dinarello. 1981. Ability of human leukocytic pyrogen to enhance phytohemoglutinin induced murine thymocyte proliferation. Cell. Immunol. 63:134-142.

5. Murphy, P. A., P. L. Senior, and W. F. Willoughby. 1980. Endogenous pyrogens made by rabbit peritoneal exudate cells are identical with lymphocyte-activating factors made by rabbit alveolar macrophages. J. Immunol. 124(5):2498-2501.

6. Klempner, M. S., C. A. Dinarello, W. R. Henderson, and J. I. Gallin. 1979. Stimulation of neutrophil oxygen-dependent metabolism by human leukocytic pyrogen. J. Clin. Invest. 64:996-1002.

7. Klempner, M. S., C. A. Dinarello, and J. I. Gallin. 1978. Human leukocytic pyrogen induces release of specific granule contents from human neutrophils. J. Clin. Invest. 61:1330-1336.

8. Gery, I., R. K. Gershon, and B. H. Waksman. 1972. Potentiation of the T-lymphocyte response to mitogens. J. Exp. Med. 136:128-155.

9. Smith, K. A., K. J. Gilbride, and M. F. Favata. 1980. Lymphocyte activating factor promotes T-cell growth factor production by cloned murine lymphoma cells. Nature (Lond.). 287:853-855.

10. Maizel, A. L., S. R. Mehta, R. J. Ford, and L. B. Lachman. 1981. Effect of interleukin-1 on human thymocytes and purified human T cells. J. Exp. Med. 153:470-475.

11. Rosenberg, S. A., and P. E. Lipsky. 1981. The role of monocytes in pokeweed mitogen-stimulated human B-cell activation: separate requirements for intact monocytes and a soluble monocyte factor. $J$. Immunol. 126:1341-1345.

12. Whisler, R. L., Y. G. Newhouse, and L. B. Lachman. 1982. Heterogeneity of human monocyte subsets in the promotion of B-cell colonies and the role of interleukin-1. J. Immunol. 129:455-460.

13. Howard, M., S. B. Mizel, L. Lachman, J. Ansel, B. Johnson, and W. E. Paul. 1983. Role of interleukin-1 in anti-immunoglobulininduced B cell proliferation. J. Exp. Med. 157:1529-1543.

14. Dinarello, C. A., D. O. Marnoy, and L. J. Rosenwasser. 1983. Role of arichidonate metabolism in the immunoregulatory function of human leukocytic pyrogen/lymphocyte-activating factor/interleukin-1. J. Immunol. 130:890-895.

15. Mizel, S. B., J. M. Dayer, S. M. Krane, and S. E. Mergenhagen. 1981. Stimulation of rheumatoid synovial cell collagenase and prosta- glandin production by partially purified lymphocyte activating factor (interleukin-1). Proc. Natl. Acad. Sci. USA. 78:2474-2477.

16. Korn, J. H., P. V. Halushka, and E. C. LeRoy. 1980. Mononuclear cell modulation of connective tissue function. Suppression of fibroblast growth by stimulation of endogenous prostaglandin production. J. Clin. Invest. 65:543-554.

17. Sztein, M. B., S. N. Vogel, J. D. Sype, P. A. Murphy, S. B. Mizel, J. J. Oppenheim, and D. L. Rosenstreich. 1981. The role of macrophages in the acute-phase response: SAA inducer is closely related to lymphocyte activating factor and endogenous pyrogen. Cell. Immunol. 63:164-176.

18. Schmidt, J. A., S. B. Mizel, D. Cohen, and I. Green. 1982. Interleukin-1, a potential regulator of fibroblast proliferation. J. Immunol. 128:2177-2182.

19. Hunninghake, G. W., J. E. Gadek, O. Kawanami, V. J. Ferrans, and R. G. Crystal. 1979. Inflammatory and immune processes in the human lung in health and disease: evaluation by bronchoalveolar lavage. Am. J. Pathol. 97:149-206.

20. Mayernik, D. G., A. Ul-Haq, and J. J. Rinehart. 1983. Differentiation-associated alteration in human monocyte-macrophage accessory cell function. J. Immunol. 130:2157-2160.

21. Ettensohn, D. B., and N. J. Roberts, Jr. 1983. Human alveolar macrophage support of lymphocyte responses to mitogens and antigens. Am. Rev. Respir. Dis. 128:516-522.

22. Toews, G. B., W. Vial, G. Nuez, P. Stastny, and M. F. Lipcomb. 1982. Alveolar macrophages from normal volunteers regulate T-lymphocyte responses. Am. Rev. Respir. Dis. 125:54A. (Abstr.)

23. Meltzer, M. S., and J. J. Oppenheim. 1977. Bidirectional amplification of macrophage-lymphocyte interactions: enhanced lymphocyte activation factor production by activated adherent mouse peritoneal cells. J. Immunol. 118:77-82.

24. Pinkston, P., P. B. Bitterman, and R. G. Crystal. 1983. Spontaneous release of interleukin-2 by lung T-lymphocytes in active pulmonary sarcoidosis. N. Engl. J. Med. 308:793-800.

25. Gillis, S., M. M. Ferm, W. Ou, and K. A. Smith. 1978. T cell growth factor: parameters of production and a quantitative microassay for activity. J. Immunol. 120:2027-2032.

26. Duff, G. W., and E. Atkins. 1982. The detection of endotoxin by in vitro production of endogenous pyrogen: comparison with limulus amebocyte lysate gelation. J. Immunol. Methods. 52:323-331.

27. Wood, D. D., and P. M. Cameron. 1978. The relationship between bacterial endotoxin and human B cell-activating factor. $J$. Immunol. 121:53-60.

28. Demenkoff, J. H., M. J. Ansfield, H. B. Kaltreider, and E. Adam. 1980. Alveolar macrophage suppression of canine bronchoalveolar lymphocytes: the role of prostaglandin $E_{2}$ in the inhibition of mitogen responses. J. Immunol. 124:1365-1370.

29. Weiner, M. S., C. Bianco, and V. Nusenzweig. 1973. Enhanced binding of neuraminidase-treated sheep erythrocytes to human T-lymphocytes. Blood. 42:939-946.

30. Ledbetter, J. A., R. L. Evans, M. Lipinski, C. CunninghamRundles, R. A. Good, and L. A. Herzenberg. 1981. Evolutionary conservation of surface molecules that distinguish $\mathrm{T}$ lymphocyte helper/ inducer and $T$ cytotoxic/suppressor subpopulations in mouse and man. J. Exp. Med. 153:310-323.

31. Rennard, S. I., G. W. Hunninghake, P. B. Bitterman, and R. G. Crystal. 1981. Production of fibronectin by the human alveolar macrophage: mechanism for the recruitment of fibroblasts to sites of 
tissue injury in interstitial lung diseases. Proc. Natl. Acad. Sci. USA. 78:7147-7151.

32. Laemmli, U. K. 1970. Cleavage of structural proteins during the assembly of the head of bacteriophage. Nature (Lond.). 277:680685.

33. Bonner, W. M., and R. A. Laskey. 1974. A film detection method for tritium-labelled proteins and nucleic acids in polyacrylamide gels. Eur. J. Biochem. 46:83-88.

34. Blyden, G., and R. E. Handschumacher. 1977. Purification and properties of human lymphocyte activating factor (LAF). $J$. Immunol. 118:1631-1638.

35. Lachman, L. B., J. O. Moore, and R. S. Metzgar. 1978. Preparation and characterization of lymphocyte-activating factor (LAF) from acute monocytic and myelomonocytic leukemia cells. Cell. Immunol. 41:199-206.

36. Flynn, A., J. H. Finke, and M. L. Hilfiker. 1982. Placental mononuclear phagocytes as a source of interleukin-1. Science (Wash. DC). 218:475-477.

37. Butler, R. H., R. P. Revoltella, P. Musiani, and M. Piantelli. 1983. Constitutive production of interleukin-1 by the human continuous cell line, CM-5. Cell. Immunol. 78:368-374.

38. Simon, P. L., and W. F. Willoughby. 1981. The role of subcellular factors in pulmonary immune function: physiochemical characterization of two distinct species of lymphocyte-activating factor produced by rabbit alveolar macrophages. J. Immunol. 126:15341541.

39. Ulrich, F. 1977. Studies of lymphocyte activating factor from alveolar macrophages. J. Reticuloendothel. Soc. 21:33-51.

40. Mizel, S. B., J. J. Oppenheim, and D. L. Rosenstreich. 1978.
Characterization of lymphocyte-activating factor (LAF) produced by a macrophage cell line, P388D1. J. Immunol. 120:1504-1508.

41. Atkins, E., P. Bodel, and L. Francis. 1967. Release of an endogenous pyrogen in vitro from rabbit mononuclear cells. J. Exp. Med. 126(2):357-383.

42. Blussé, van Oud Alblas, A., B. van der Linden-Schrever, and R. van Furth. 1981. Origin and kinetics of pulmonary macrophages during an inflammatory reaction induced by intravenous administration of heat-killed bacillus calmette-guerin. J. Exp. Med. 154:235-252.

43. Newman, S. L., R. A. Musson, and P. M. Henson. 1980. Development of functional complement receptors during in vitro maturation of human monocytes into macrophages. J. Immunol. 125:2236.

44. Musson, R. A., H. Shafran, and P. M. Henson. 1980. Intracellular levels and stimulated release of lysosomal enzymes from human peripheral blood monocytes and monocyte derived macrophages. $J$. Reticuloendothel. Soc. 28:249.

45. Alitalo, K., H. Tapani, and A. Vaheri. 1980. Fibronectin is produced by human macrophages. J. Exp. Med. 151:602-613.

46. Salahuddin, S. Z., P. D. Markham, and R. C. Gallo. 1982. Establishment of long-term monocyte suspension cultures from normal human peripheral blood. J. Exp. Med. 155:1842-1857.

47. Lee, K.-C., M. Wong, and D. McIntyre. 1981. Characterization of macrophage subpopulations responsive to activation by endotoxin and lymphokines. J. Immunol. 126:2474-2479.

48. Dinarello, C. A., and L. J. Rosenwasser. 1980. Lymphocyte activating property of human leukocytic pyrogen. In Advances in Immunopharmacology. J. Hadden, L. Chedid, P. Mullen, and F. Spreatico, editors. Pergamon Press Inc., Elmsford, NY. 419-425. 